\title{
COMPARISON OF CHARACTERISTICS OF 3D LASER SCANNER FOR CONSTRUCTION OF INDOOR GEOSPATIAL INFORMATION
}

\author{
Keun Wang Lee ${ }^{1}$ and Joon Kyu Park ${ }^{2 *}$ \\ ${ }^{1}$ Department of Multimedia Science, Chungwoon University, 113, \\ Sukgol-ro Nam-gu, Incheon, Korea \\ ${ }^{2}$ Department of Civil Engineering, Seoil University, 28, Yongmasan-ro 90-gil, \\ Jungnang-gu, Seoul, Korea \\ ${ }^{1}$ kwlee@chungwoon.ac.kr, ${ }^{2}$ jkpark@ seoil.ac.kr
}

\begin{abstract}
Recently, the design and operation of buildings and various ICT technologies have developed and the interior space has become larger and more complex. As a result, a variety of activities such as convention, shopping, and entertainment are carried out without moving outdoors and the cost of living in the indoor space is gradually increasing. In addition, as the services for indoor space are diversified, research on technology for construction of effective indoor geospatial information is needed. In this study, the characteristics of 3D laser scanner which is widely used for spatial information construction was investigated. 3D laser scanner for construction of indoor geospatial information can be divided into static scanner, mobile mapping scanner and handheld scanner. Mobile mapping scanners and handheld scanners provide continuous data acquisition compared to static scanners, and efficient data acquisition is possible. In terms of accuracy, the static scanner showed less than $1 \mathrm{~mm}$ noise on the wall, and the handheld scanner showed about $40 \mathrm{~mm}$ noise. The application of 3D laser scanner to indoor geospatial information construction considering the work flow and accuracy of related regulations is suggested. If the scanner is selected for the purpose of the indoor geospatial information that is intended to be deployed, it will be possible to establish the indoor space information effectively, considering the work efficiency or accuracy of the performance.
\end{abstract}

Keywords-3D Laser Scanner, Geospatial Information, Mobile Mapping System, Point Cloud, Simultaneous Localization and Mapping

\section{INTRODUCTION}

Recently, According to a report by the US Environmental Protection Agency, it is known that on average, about $80 \%$ of the total life is done indoors $[1,2]$. Recently, the design and operation of buildings and various ICT technologies have developed and the interior space has become larger and more complex [3, 4]. As the various activities such as conventions, shopping and entertainment are carried out without moving outdoors, the cost of living in the indoor space is gradually increasing. The range of the geospatial information service target area is rapidly expanding from the outdoor space to the indoor space. These changes will lead to the development of advanced technologies such as IT and mobile and the utilization of various services such as portal service of indoor space

Received: May 8, 2019

Reviewed: July 19, 2019

Accepted: August 2, 2019

* Corresponding Author 
information support for the disabled, disaster response, subway service etc., [5, 6]. Therefore, the importance of indoor space as a new part where various services are converged is getting more and more important. In recent years, techniques for building indoor geospatial information have been introduced [7, 8]. The 3D laser scanner is a technique to measure distance using a laser, and it is increasingly being used to visualize and construct 3D geospatial information [9, 10]. Since the 1970s, laser scanning techniques have been developed due to the development of laser technology, and their use is increasing due to higher measurement distance and spatial resolution than microwave $[11,12]$. In this study, 3D laser scanner for construction of indoor geospatial information was investigated and analyzed. Figure 1 shows the study flow of this study.

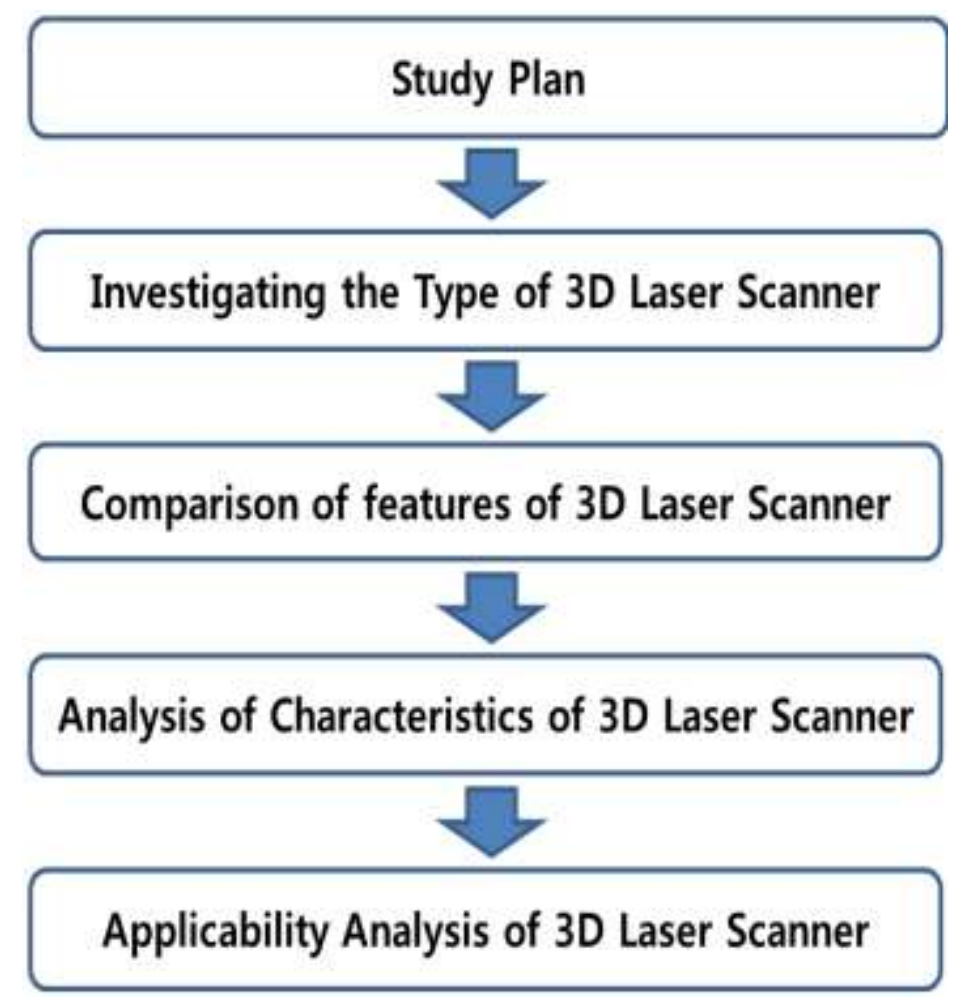

Fig. 1 Study Flow

\section{3D LASER SCANNER FOR CONSTRUCTION OF INDOOR GEOSPATIAL INFORMATION}

The 3D laser scanner basically can be divided into a laser transceiver, a laser detector, and a part for signal acquisition and processing and data transmission and reception [13]. Also, it is divided into a TOF(Time-Of-Flight) method and a phase-shift method according to a modulation method of a laser signal. The TOF method is to measure the distance by measuring the time that the laser emits a pulse signal and the reflected pulse signals from objects within the measurement range arrive at the receiver. The phase-shift is a method of calculating time and distance by emitting a continuously modulated laser beam having a specific frequency and measuring a phase change amount of a signal reflected from an object within a measurement range [14]. In previous studies, 3D laser scanners were also referred to as LiDAR(Light Detection And Ranging) [15]. Table I shows types of LiDAR technologies [16]. 
Table I. Types of LiDAR Technologies

\begin{tabular}{|c|l|}
\hline Type. & \multicolumn{1}{c|}{ Description } \\
\hline Elastic-backscatter LiDAR & $\begin{array}{l}\text { Techniques used to measure the aerosol and cloud characteristics of the } \\
\text { atmosphere using the spectral spreading characteristics of backscattered light } \\
\text { according to the momentum of particles without changing the laser wavelength }\end{array}$ \\
\hline Raman LiDAR & $\begin{array}{l}\text { Technology used for measurement of atmospheric water vapor and temperature } \\
\text { distribution through analysis of frequency distribution of laser light scattered } \\
\text { according to molecular energy state and intensity distribution in Raman band }\end{array}$ \\
\hline Differential-absorption LiDAR & $\begin{array}{l}\text { Technology that can measure the concentration distribution of air pollutants using } \\
\text { difference of laser beams having different laser wavelengths }\end{array}$ \\
\hline Resonance fluorescence LiDAR & $\begin{array}{l}\text { Technique for measuring atomic and ionic concentrations in the medium region } \\
\text { using laser light having the same energy as the energy transition of atoms, ions, or } \\
\text { molecules and emitting light of the same wavelength or long wavelength. }\end{array}$ \\
\hline Doppler LiDAR & $\begin{array}{l}\text { Technique to measure the velocity of the wind by measuring the minute frequency } \\
\text { change of the laser beam by Doppler effect }\end{array}$ \\
\hline Laser rangefinder & $\begin{array}{l}\text { LiDAR technology to measure the distance by measuring the laser beam reception } \\
\text { time from an object }\end{array}$ \\
\hline
\end{tabular}

In this study, characteristics of static, handheld, and mobile mapping scanners suitable for indoor geospatial information among 3D laser scanners were analyzed. The 3D laser scanners used in the study consist of static, handheld, and MMS(Mobile Mapping System). Fig. $2 \sim$ Fig. 4 shows the scanners and Table II shows specification of 3D laser scanners.

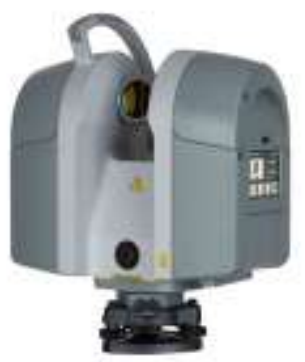

Fig. 2. Static Scanner[17]

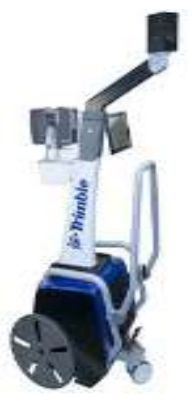

Fig. 3. MMS[17]

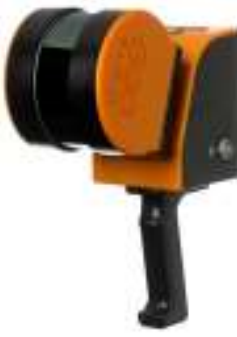

Fig. 4. Handheld Scanner[19]

Table II. Specification of 3D Laser Scanners[17,19]

\begin{tabular}{|c|c|c|c|}
\hline Item & Static Scanner & Mobile Mapping Scanner & Handheld Scanner \\
\hline Method & TOF & Phase-shift & Phase-shift \\
\hline Laser & Class 1 & Class 1 & Class 1 \\
\hline Size & $335 \times 386 \times 242 \mathrm{~mm}$ & $1730 \times 2210 \times 880 \mathrm{~mm}$ & $216 \times 108 \times 266 \mathrm{~mm}$ \\
\hline Range & $340 \mathrm{~m}$ & $130 \mathrm{~m}$ & $100 \mathrm{~m}$ \\
\hline Weight & $11.2 \mathrm{~kg}$ & $49.5 \mathrm{Kg}$ & $2.76 \mathrm{~kg}$ \\
\hline Distance Accuracy & $2 \mathrm{~mm}$ & $2 \mathrm{~mm}$ & $30 \mathrm{~mm}$ \\
\hline Angle Accuracy & $16 ”$ & $32 ”$ & - \\
\hline Working Time & $1 \mathrm{~min} \sim 14 \mathrm{~min} / \mathrm{station}$ & $2 \mathrm{hour}$ & $30 \mathrm{~min}$ \\
\hline Speed & $1,000,000 \mathrm{pts} / \mathrm{s}$ & $1,000,000 \mathrm{pts} / \mathrm{s}$ & $300,000 \mathrm{pts} / \mathrm{s}$ \\
\hline Distance & $0.6-340 \mathrm{~m}$ & $0.6-130 \mathrm{~m}$ & $100 \mathrm{~m}$ \\
\hline Battery & $2 \mathrm{hour}$ & $4.5 \mathrm{hour}$ & $3 \mathrm{hour}$ \\
\hline FOV & $360 \times 317($ degree $)$ & $360 \times 300($ degree $)$ & $360 \times 270(\mathrm{degree})$ \\
\hline Color & O & O & X \\
\hline IP & IP54 & IP52 & IP54
\end{tabular}


As shown in Table II, each scanner is different in size, weight and accuracy. The workflow of static and other scanners is also different. Static 3D laser scanners need to be installed and moved repeatedly, but mobile mapping scanners and handheld scanners are able to acquire continuous data. Figure 5 shows the data acquisition method of the static scanner and the other scanners.

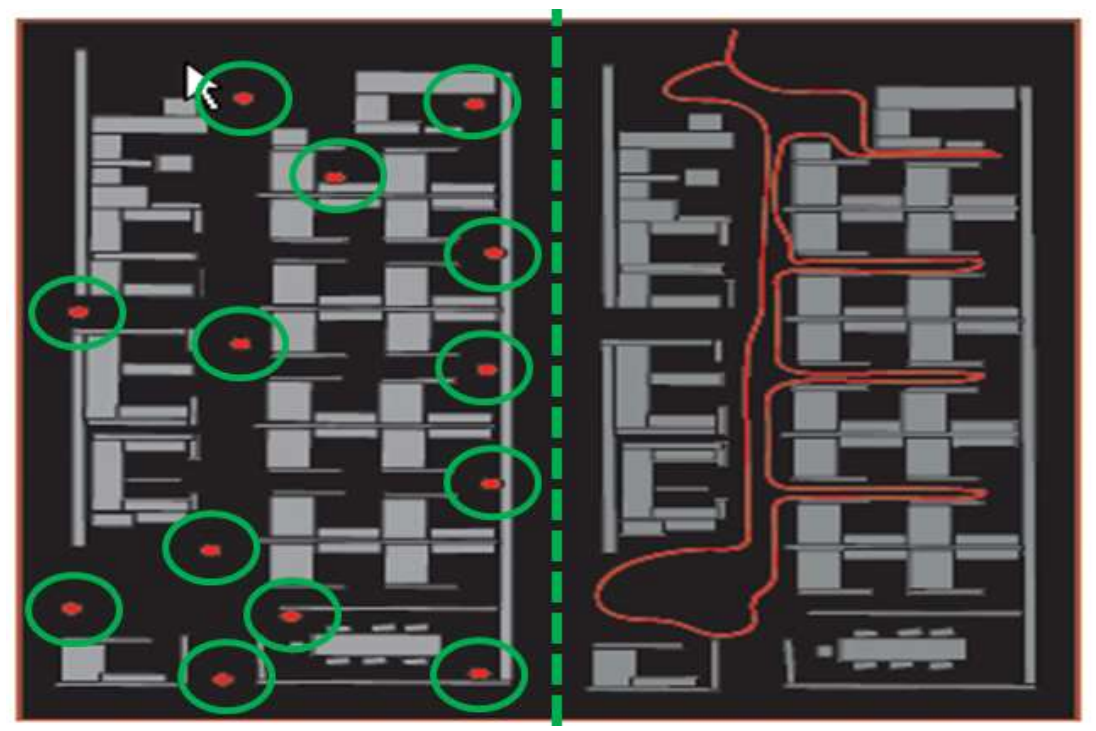

Fig. 5 Data Acquisition Method of the Static Scanner and the Other Scanners

As shown in Table II, each scanner is different in size, weight and accuracy. The workflow of static and other scanners is also different. Static 3D laser scanners need to be installed and moved repeatedly, but mobile mapping scanners and handheld scanners are able to acquire continuous data. Fig. 6 shows the data acquisition method of the static scanner and the other scanners. The mobile mapping scanner and the handheld scanner are able to acquire data at a much higher rate than the static scanner because they can acquire continuous data. In the case of Fig. 6 , it is possible to save about $80 \%$ of the time when acquiring indoor geospatial information. The larger the workspace, the larger the time difference and the more efficient the handheld scanner. However, handheld scanners have a low accuracy and require confirmation before operation. Table III shows the comparison of data acquisition time.

Table III. Comparison of Data Acquisition Time

\begin{tabular}{|c|c|c|}
\hline Item & Static Scanner & Mobile Mapping \& Handheld Scanner \\
\hline Installation & $5 \min$ x number of points & $5 \mathrm{~min}$ \\
\hline Moving & $15 \mathrm{~min}$ x number of points & Continuous acquisition \\
\hline $\begin{array}{c}\text { Data } \\
\text { Acquisition }\end{array}$ & $5 \min$ x number of points & $60 \mathrm{~min}$ \\
\hline
\end{tabular}

\section{COMPARISON OF CHARACTERISTICS OF 3D LASER SCANNER}

To compare the characteristics of the 3D laser scanner, we compared the data of the static scanner and the mobile mapping scanner. Data in the same building was acquired through each scanner. Figure 6 show the data acquired through each scanner. 


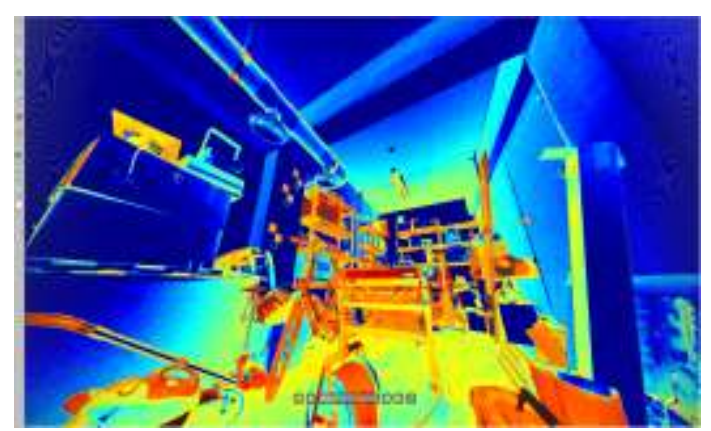

(a) Static Scanner

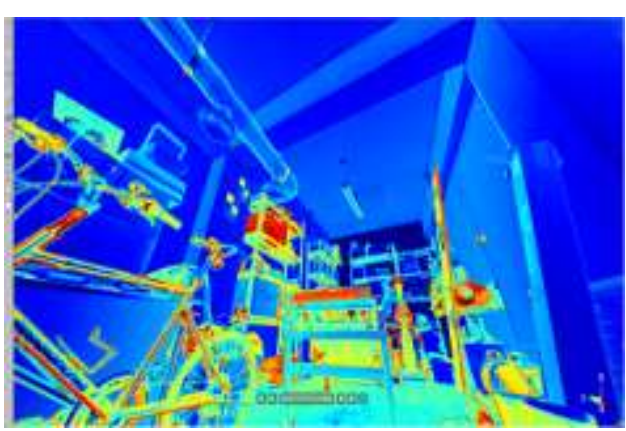

(b) Mobile Mapping Scanner

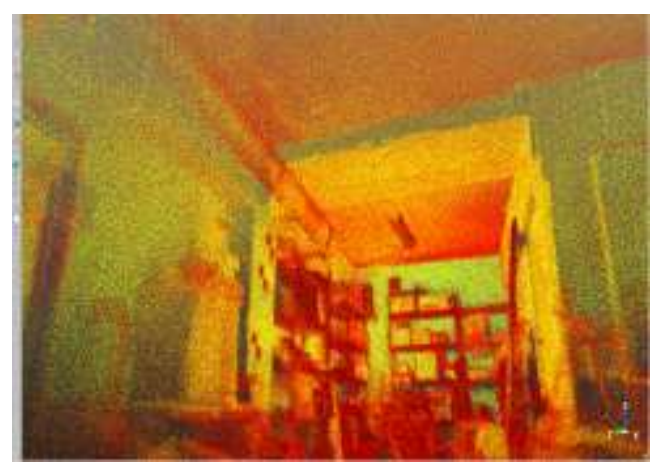

(c) Mobile Mapping Scanner

Fig. 6 Data Acquired with Each Scanner

In general, the TOF method is known to have higher accuracy than the phase-shift method [12]. However, this is largely influenced by the distance, and in the construction of the indoor geospatial information, the data difference of the two methods did not appear much. Figure 7 compares the Static scanner with the mobile mapping scanner data. Red is the data of static scanner, and green is the data of the mobile mapping scanner.
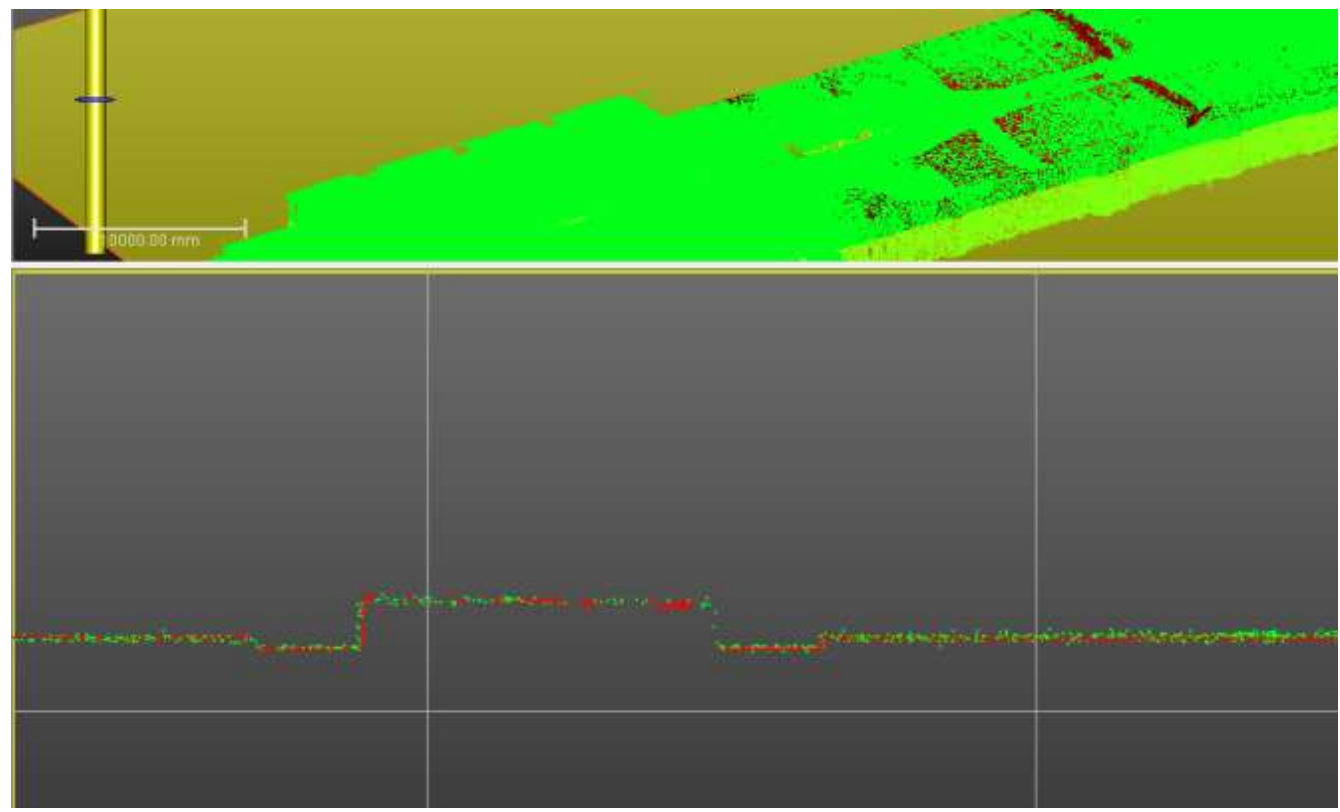

Fig. 7 Comparison of TOF and Phase-shift Scanner data 
In this study, we compared the data of static scanner, mobile mapping scanner and handheld scanner to analyse the characteristics of scanner for indoor spatial information construction. The data of the handheld scanner showed that the density of the point cloud was lower than that of the other scanner's data, and the noise was larger. Figure 8 shows comparison between the handheld scanner and the other scanner's data.
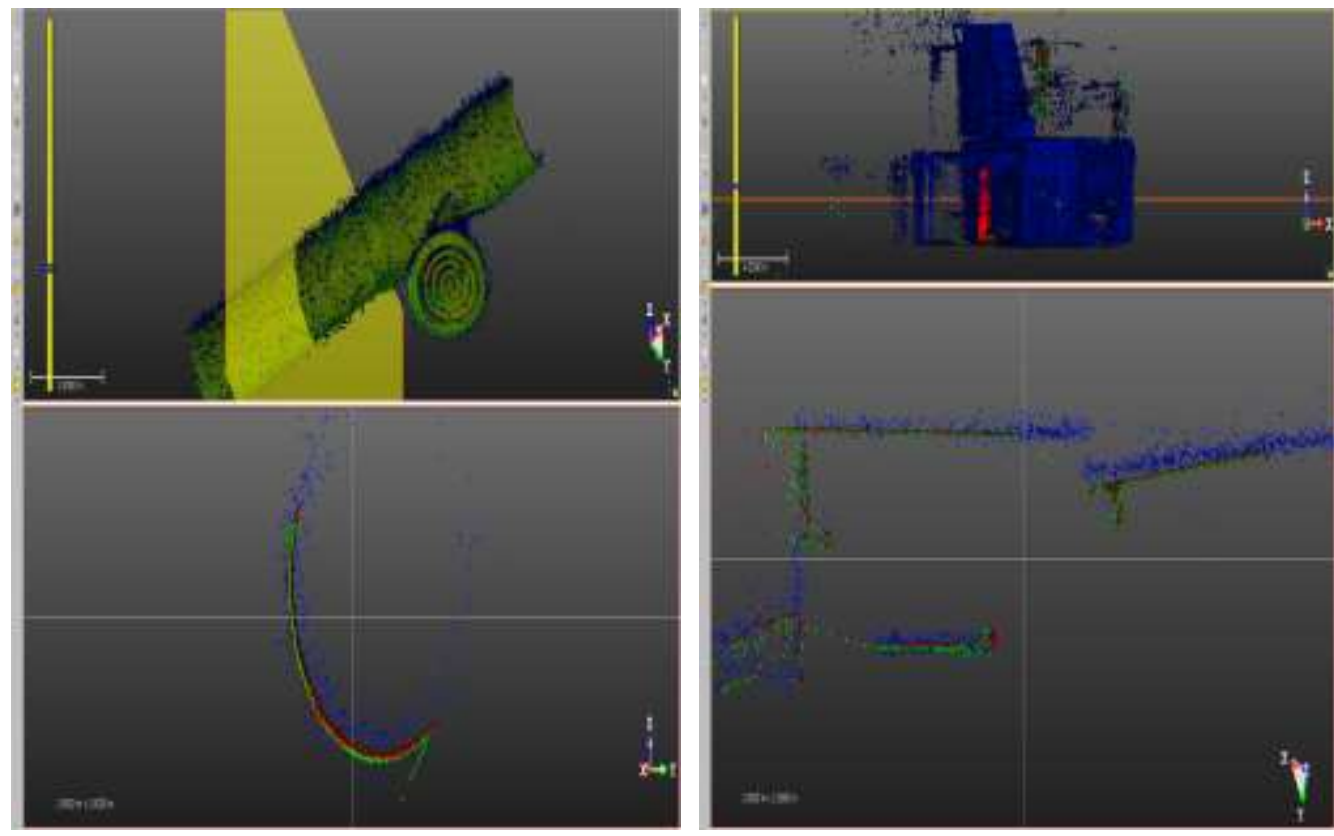

Fig. 8 Comparison between the Handheld Scanner and the Other Scanner's data

Red points indicate static scanner's data, green points indicate mobile mapping scanner's data, and blue points indicate handheld scanner data. The data of the static scanner and the mobile mapping scanner showed no significant difference, but the data of the handheld scanner showed a tendency to be thick in cross section.

To compare the static scanner data with the handheld scanner data, the point cloud data and the result of creating the line for the wall were compared. Figure 9 and Figure 10 represent the comparison of the point cloud and the line.

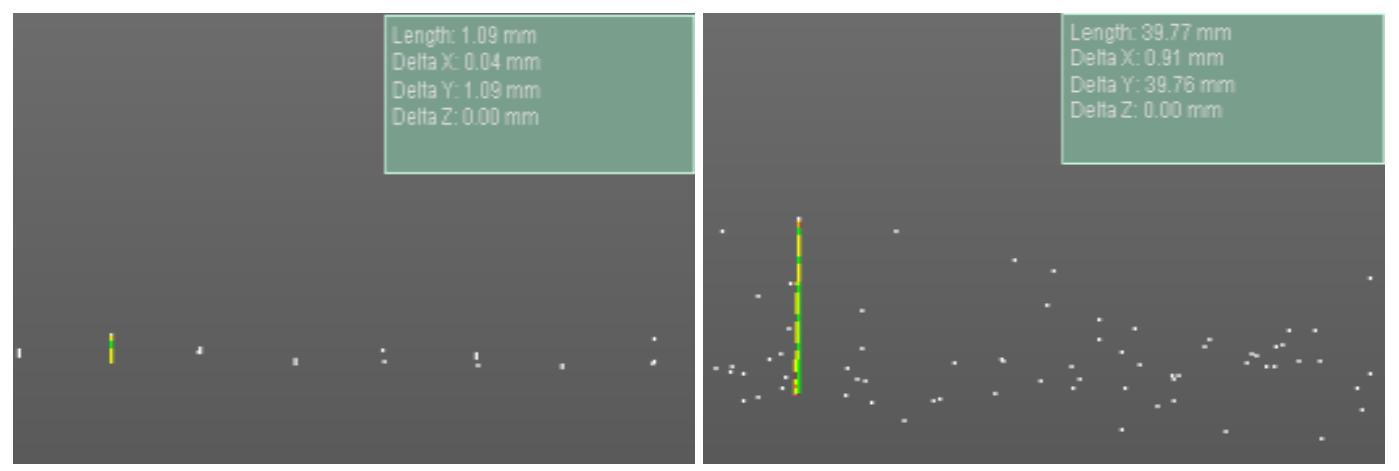

Fig. 9 Point Cloud Comparison (Static Scanner and Handheld Scanner) 

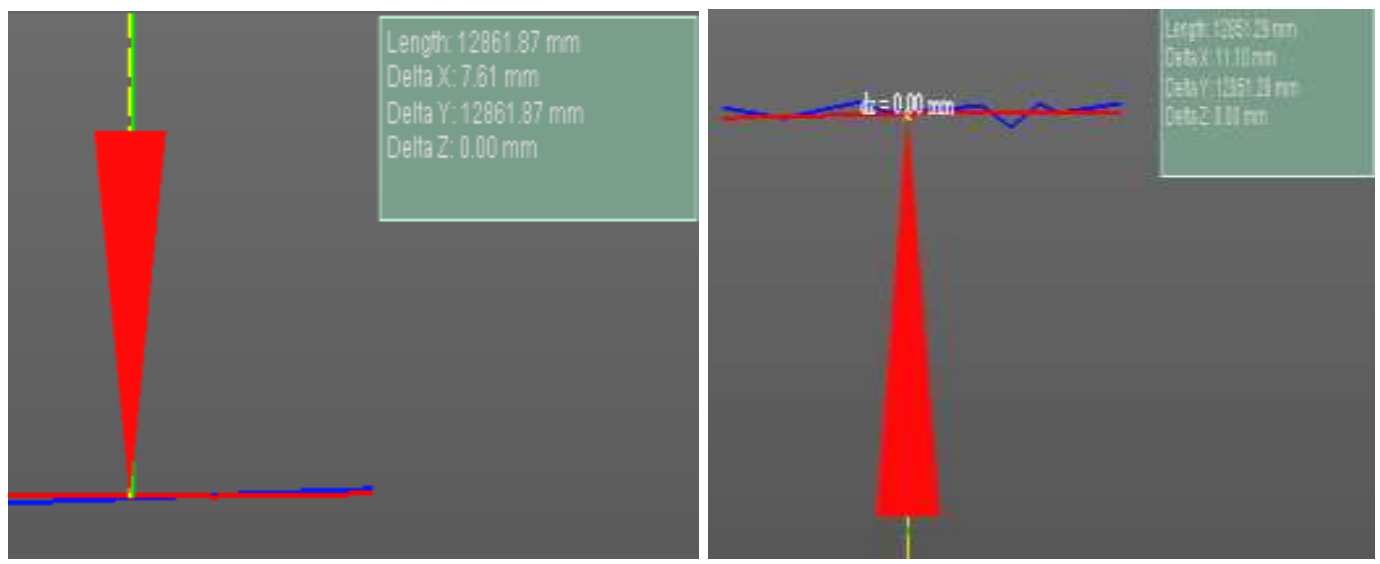

Fig. 10. Line Comparison (Static Scanner and Handheld Scanner)

As shown in Figure 10 and Figure 11, the static scanner showed about $1 \mathrm{~mm}$ of noise, but the handheld scanner showed about $40 \mathrm{~mm}$ of noise. These results are due to the performance of each scanner and are similar to the accuracy of each scanner shown in Table 2. The speed of the work for the construction of Indoor Geospatial Information is more effective in the data acquisition time and data processing of the handheld scanner. For the study site, the mobile mapping scanner and handheld scanner took about 30 minutes to acquire the data, but the static scanner took two hours. As the area for acquiring data increases, this difference will become even greater. Static scanners can build precise indoor geospatial information, but are less efficient at work, and handheld scanners can work quickly but have low precision features. In order to construct indoor geospatial information using a 3D laser scanner, it is necessary to select a method considering operation efficiency and accuracy.

\section{APPLICABILITY ANALYSIS of 3D LASER SCANNER FOR CONSTRUCTION OF INDOOR GEOSPATIAL INFORMATION}

To analyse the applicability of 3D laser scanner for construction of indoor geospatial information, the workflows specified in the relevant regulations were compared. The related regulation is "Regulation on construction of indoor space information". This regulation also defines LOD (Level Of Detail). The definition of each LOD is shown in Table IV[20].

Table IV. Definition of LOD

\begin{tabular}{|c|l|}
\hline LOD & \multicolumn{1}{c|}{ Definition } \\
\hline LOD0 & $\begin{array}{l}\text { - Two-dimensional representation of indoor space } \\
\text { - Multilayer structure to represent multiple layers separately }\end{array}$ \\
\hline LOD1 & $\begin{array}{l}\text { - Indoor objects are represented by a simplified three-dimensional model in box form } \\
\text { - Vertical structure is given height value by using automation tool }\end{array}$ \\
\hline LOD2 & $\begin{array}{l}\text { - Describe indoor objects in a detailed three-dimensional model } \\
\text { - Separate walls, ceilings and floors } \\
\text { - Describes interior objects on walls, ceilings, and floors in relation to walls, ceilings, and floors }\end{array}$ \\
\hline LOD3 & - Textual mapping of real images in addition to LOD2 \\
\hline
\end{tabular}

LOD0 is a two-dimensional plan view, and LOD1 to LOD3 are three-dimensional geospatial information. LOD0 does not represent facilities, and LOD1 includes location (X, Y). LOD2 and LOD3 contain positions $(\mathrm{X}, \mathrm{Y}, \mathrm{H})$ of facilities. Figure 11 shows examples of LOD[20]. 


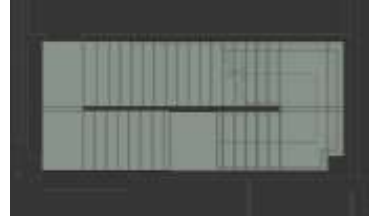

(a) LOD1

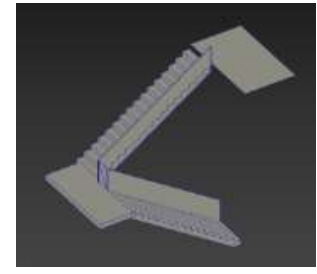

(b) LOD2

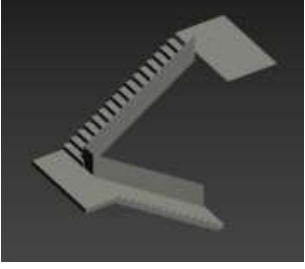

(c) LOD3

Fig. 11 Example of LOD

In this study, the scope of application of LOD-specific workflow and scanner was presented based on the study results to demonstrate the applicability of indoor spatial information using 3D laser scanner. Figure 13 shows LOD-related workflow and scanner coverage.

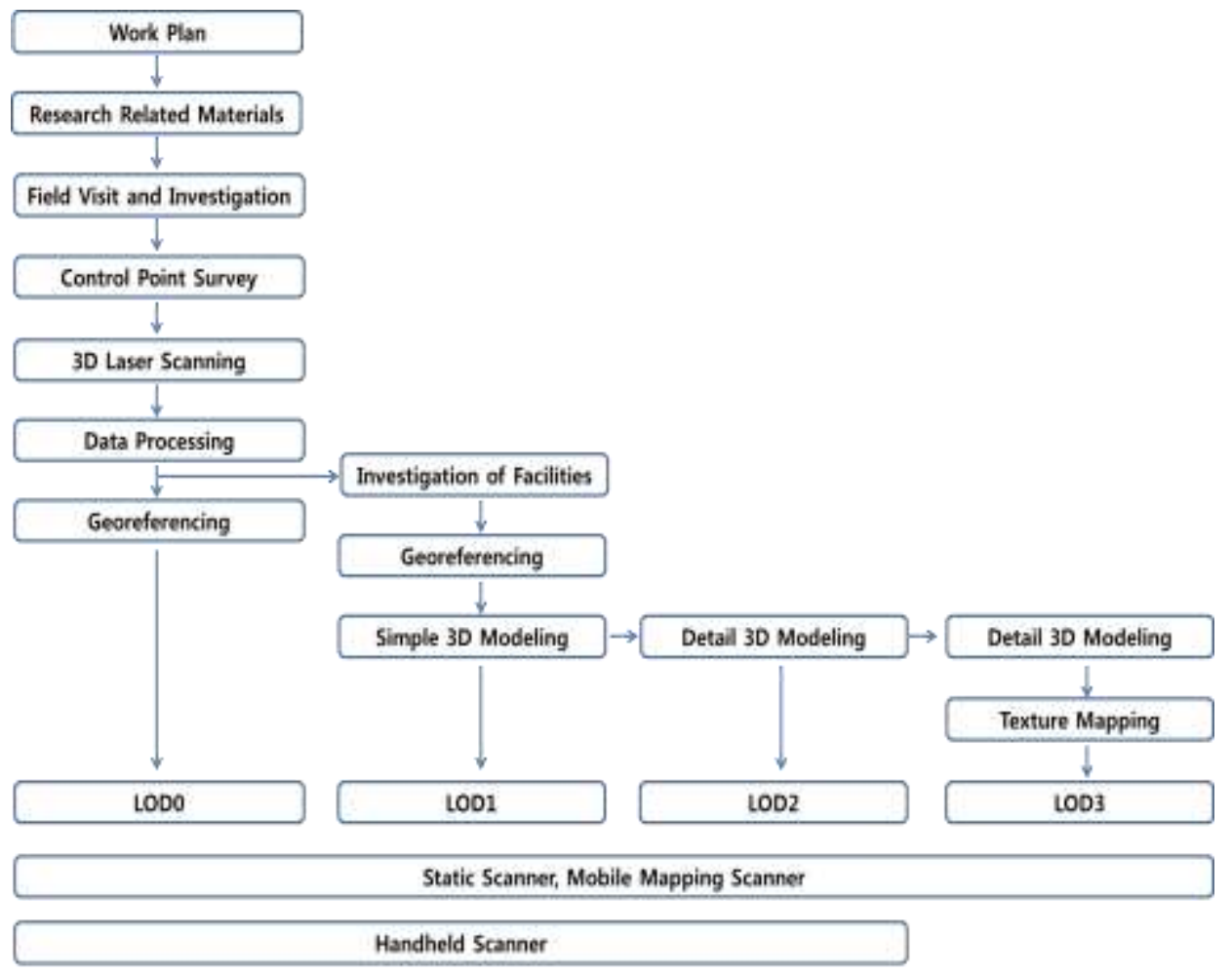

Fig. 13 LOD-related Workflow and Coverage of Scanners

The handheld scanner requires an additional camera for texture mapping for the production of LOD3. Depending on the workflow, the scope of application of the 3D laser scanner has been derived, but it is necessary to consider the accuracy as defined in the related regulations. The accuracy defined in the relevant regulations is within $0.7 \mathrm{~m}$ horizontal and $0.33 \mathrm{~m}$ vertically.

In this study, a relative comparison was made with accuracy. The accuracy of the data acquired by each scanner was evaluated based on the design drawing. Table V shows the deviation from the design drawings for the distance between the walls.

Table V. Deviation from the Design Drawings for the Distance between the Walls

\begin{tabular}{|l|c|c|c|}
\hline Scanner & Static Scanner & Mobile Mapping Scanner & HandHeld Scanner \\
\hline Deviation & $0.005 \mathrm{~m}$ & $0.006 \mathrm{~m}$ & $0.02 \mathrm{~m}$ \\
\hline
\end{tabular}


The accuracy of the static scanner, the mobile mapping scanner, and the handheld scanner satisfies the range specified by the related regulations, and thus the scanner can be utilized.

\section{CONCLUSION}

In this study, 3D laser scanner for construction of indoor geospatial information was investigated and analyzed. 3D laser scanner for construction of indoor geospatial information can be divided into static scanner, mobile mapping scanner and handheld scanner. Mobile mapping scanners and handheld scanners provide continuous data acquisition compared to static scanners, and efficient data acquisition is possible because of the short time required to install the device. The static scanner showed less than $1 \mathrm{~mm}$ noise on the wall, and the handheld scanner showed about $40 \mathrm{~mm}$ noise. The application of 3D laser scanner to indoor geospatial information construction considering the work flow and accuracy of related regulations is suggested. If the scanner is selected for the purpose of the indoor geospatial information that is intended to be deployed, it will be possible to establish the indoor space information effectively, considering the work efficiency or accuracy of the performance.

\section{ACKNOWLEDGMENTS}

This research was supported by Basic Science Research Program through the National Research Foundation of Korea(NRF) funded by the Ministry of Science and ICT(No. NRF-2018R1C1B6004021).

\section{REFERENCES}

[1] M. K. Chung, C. J. Kim, K. H. Choi, D. K. Chung and Y. I. Kim, "Development of LiDAR Simulator for Backpack-mounted Mobile Indoor Mapping System", Journal of the Korean Society of Surveying, Geodesy, Photogrammetry and Cartography, 35.2(2017): 91-102.

[2] J. H. Han and S. H. Lee, "An Analysis on the Change of Smart City Space: Convergence Change of District, Street, Building and Facility", Journal of the Korea Academia-Industrial cooperation Society, 19.5(2018): 537-550.

[3] G. Ko, K. W. Suh, and S. H. Nam, "A Study on a Drawing Tool of a Spatial Drawing Application in Virtual Reality", International Journal of Multimedia and Ubiquitous Engineering, 13.4(2018): 7-12.

[4] W. Kong, "Analyzing the Usage of Data Mining in Spatial Database", International Journal of Internet of Things and its Applications, 1.1(2017): 1-12.

[5] J. J. Kim, Y. S. Lee, J. Y Moon, and J. M. Park, "Bigdata based Network Traffic Feature Extraction”, International Journal of Communication Technology for Social Networking Services, 6.1(2018): 1-6.

[6] V. Ragu, Y. H. Kim, K. S Chae, J. W. Park, Y. Y. Cho, S. Y. Yang, and C. S. Shin, "A Best Fit Model for Forecasting Korea Electric Power Energy Consumption in IoT Environments", International Journal of Internet of Things and its Applications, 2.1(2018): 7-12.

[7] J. Y. Nam, C. W. Jo and S. H. Park, "A Study on Applying Information Framework for BIM Based WBS -Focusing on Civil Construction”, Journal of the Korea Academia-Industrial cooperation Society, 18.11(2017): 770-777.

[8] H. Yang and C. Yang, "Modeling and Testing for CNC Machine Tool Spindle Static and Dynamic Characteristic Based on FEM", International Journal of Computer-aided Mechanical Design and Implementation, 4.2(2018): 21-32.

[9] J. K. Park and K. W. Lee, "Analysis of Geospatial Information Construction Efficiency by 3D Laser Scanner Integrated with Total Station", Journal of the Korea Academia-Industrial cooperation Society, 18.12(2017): 638-643.

[10] S. H. Ju, S. H. Yoon, S. Y. Park and J. Heo, "Simulation based Target Geometry Determination Method for Extrinsic Calibration of Multiple 2D Laser Scanning System", Journal of the Korean Society of Surveying, Geodesy, Photogrammetry and Cartography, 36.6(2018): 443-449.

[11] D. G. Lee and D. C. Lee, "Key Point Extraction from LiDAR Data for 3D Modeling", Journal of the Korean Society of Surveying, Geodesy, Photogrammetry and Cartography, 34.5(2016): 479-493.

[12] Y. K. Moon, Y. B. Shim, H. K. Song, "Error Correction Technique of Distance Measurement for ToF LIDAR Sensor", KSII Transactions on Internet and Information Systems, 12.2(2018): 960-973.

[13] J. K. Park and M. G. Kim, "Application of scanning total station for efficiency enhancement of tunnel surveys”, Journal of the Korea Academia-Industrial cooperation Society, 18.4(2017): 242-247. 
[14] H. Y. Kang, S. K. Nam, J. R. Hwang and J. Y. Lee, "LOD(Level of Detail) Model for Utilization of Indoor Spatial Data", Journal of the Korean Society of Surveying, Geodesy, Photogrammetry and Cartography, 36.6(2018): 545-554.

[15] T. H. Kim, D. U. Seo and K. J. Li, "Generation Method of CityGML Using IndoorGML”, Journal of the Korea Society for Geospatial Information System, 25.3(2017): 23-34.

[16] J. Y. Lim, J. M. Lee, D. H. Kim, and J. D. Kim, "Performance Analysis of LoRa(Long Range) according to the Distances in Indoor and Outdoor Spaces", Journal of the Korean Institute of Information Scientists and Engineers, 44.7(2017): 733-741.

[17] Trimble Navigation Ltd., (2019), http://www.trimble.com.

[18] FARO Technologies, Inc., (2019), https://www.faro.com.

[19] GeoSLAM, (2019), https://geoslam.com/.

[20] Ministry of Government Legislation, (2019), http://www.law.go.kr/. 